\title{
EU VOLTEI PARA REIMPLANTAR A TUA MEMÓRIA: PARA OS QUE NÃO OUVIRAM
}

Gabriela Kvacek Betella

\section{RESUMO}

Os registros orais, desprovidos de grande elaboração retórica, marcam os relatos familiares e os depoimentos sobre episódios marcantes e particularidades aparentemente menores dos grandes conflitos, como a Segunda Guerra Mundial. A memória oral cumpriu uma importante função de transmissão da história, especialmente ao legar para o registro escrito a sistematização dos testemunhos, revelando memórias pessoais na forma de cartas, diários e narrativas, além de se incorporar a várias obras de ficção. Neste trabalho apresentamos o valor de testemunhos de ex-partigiani reunidos no volume lo sono l'ultimo (Eu sou o último) como evocação e transmissão de lembranças pessoais extremamente ligadas ao conflito e como manifestações no âmbito literário. A valorização de uma tradição de comunicação das lembranças pelos descendentes e pelos compatriotas torna o testemunho de homens e mulheres que lutaram pela libertação de muitas localidades italianas muito mais que relato fragmentado quando os leitores interessados na memória dos que sobreviveram, integrada à micro-história dos acontecimentos, percebem a sua lógica expressiva. Exploramos tanto o sentido de testemunha adotado por Giorgio Agamben, quanto o valor estético da voz traumatizada na perspectiva de Márcio Seligmann-Silva.

Palavras-chave: Segunda Guerra Mundial. Testemunho. Representação. Io sono l'ultimo. Partigiani. 
I CAME BACK TO REIMPLANT YOUR MEMORY: FOR THOSE WHO DID NOT HEAR

\begin{abstract}
The oral records, deprived of great rhetoric elaboration, mark the family accounts and the testimonies about remarkable and apparently minor particularities of grand conflicts, like the World War II. The oral memory fulfilled an important function of historical transmission, especially in handing on to written record the organization of testimonies, revealing personal memories in the form of letters, diaries and narratives, besides of integrating itself to several works of fiction. In the present work we present the value of former partigianis testimonies collected in the volume 10 sono l'ultimo (I am the last one) as evocation and transmission of personal remembrances strongly linked to the conflict and as manifestations in the literary field as well. The valuing by descendants and fellow countrymen of a tradition of memory communication make the testimony of men and women that fought for the liberation of many Italian locations much more than fragmented reports when the interested reader in the memory of those that survived, integrated to the micro-history of the events, perceive its expressive logic. We explore both the meaning of witness adopted by Giorgio Agamben and the esthetical value of the traumatized voice in the perspective of Márcio Seligman-Silva.
\end{abstract}

Keywords: World War II. Testimony. Representation. Io sono l'ultimo. Partigiani. registradas como arte de resistência

"Oh!" il vecchio rispose "Dobbiamo imparare". "Imparare dai morti?" "Si capisce. Da chi si puo' imparare se non da loro? Loro soltanto insegnano". "Imparare che cosa?" chiese Berta. "Cos'è che insegnano?". "Quello per cui" il vecchio disse "sono morti".

Elio Vittorini, Uomini e no 


\section{INTRODUÇÃO: A RECORRÊNCIA INSISTENTE}

Peter Burke (2006) pondera que as narrativas de memória não são as próprias memórias, mas as transformações das mesmas através da escrita. Como tem sido utilizado como documento histórico, esse tipo de narrativa deve se submeter à crítica de fontes, como qualquer outra, a partir da qual os historiadores levam em conta a seleção consciente ou inconsciente dos fatos narrados, bem como as interpretações condicionadas por grupos sociais. Assim também deve ocorrer com a chamada história oral, representada pelos relatos colhidos por entrevistas, que vem cumprindo uma significativa função como documento único ou complemento de outras fontes. De qualquer forma, a memória pode ser fonte histórica na medida em que carrega história vivida e conteúdos comuns de um grupo. Novas fontes e novas metodologias dos estudos históricos têm explorado os testemunhos e as narrativas de memória, no sentido de valorizar a perspectiva do homem comum, os fatos de uma vida, interligados ao contexto do passado revisitado.

Com o final da Segunda Guerra Mundial, vários relatos reproduziram a experiência dos que passaram por algum episódio relativo ao conflito. Desde as histórias dos avós e pais que enfrentaram o racionamento de comida na cidade de São Paulo, às descrições do sofrimento nas cidades bombardeadas na Europa, a memória evocada parece cumprir o dever de transmitir uma experiência individual ou coletiva. Muitas manifestações literárias (romances, contos, memórias, cartas, diários) trataram e continuam abordando a Segunda Guerra e seus desdobramentos nos anos seguintes ao final dos combates, manifestando frequentemente na estrutura do texto alguns sinais da tradição oral. Assim também aconteceu com o cinema, pelo menos desde 1944.

Sabemos que o biênio 1943-1945 carrega episódios diferenciados e marcantes que, pela singularidade ou aberração, não deixaram de aparecer em muitas representações artísticas. Na Itália, a Resistência ocupou lugar importante na literatura e no cinema, em parte devido às marcas deixadas no povo italiano. A luta pela libertação do país toma espaço após o armistício assinado com as forças aliadas, em setembro de 1943. Com isso, os exércitos anglo-americanos que invadiam a península transformam-se em tropas de libertação e os alemães já instalados, tropas de ocupação. Com o país em pleno caos, sem comando, o exército italiano se dispersou em deserções e adesões aos grupos de guerrilha 
contra os alemães e seus aliados fascistas. Os grupos de partigiani libertaram muitas regiões da Itália, especialmente no norte, combatendo o inimigo estrangeiro ou os compatriotas fascistas.

O cinema italiano conseguiu representar ou documentar levando para as telas a temática da guerra ou do pós-guerra, com o propósito de mostrar a luta pela libertação do país. Antes mesmo de mencionar os filmes neorrealistas de Roberto Rossellini, Vittorio de Sica e Luchino Visconti, é preciso lembrar o documentário Giorni di gloria (Dias de glória, Giuseppe De Santis, Marcello Pagliero, Mario Serandrei e Luchino Visconti, 1945), que foi uma realização pioneira nesse sentido, com cenas reais, rodadas quase clandestinamente entre 1944 e 1945, ao lado de encenações que representam a resistência contra o nazismo e o fascismo, ou, como se passou a chamar na Itália após 1943, contra o nazifascismo.

A literatura revelou obras muito significativas e diversas, como o romance de forma renovadora Uomini e no (1945), de Elio Vittorini, o primeiro romance de Italo Calvino, Il sentiero dei nidi di ragno (1947), as suas narrativas curtas recolhidas em Ultimo viene il corvo (1949) e o representante de uma saga editorial, II partigiano Johnny (1968), de Beppe Fenoglio. As obras autobiográficas ou de inspiração memorialista são bastante conhecidas, como L'Agnese va a morire (1949), de Renata Viganò.

A partir dos anos de 1950 algumas iniciativas de recolhimento de testemunhos de combatentes, revelam não somente o profundo sentimento de resistência dos que lutaram, como certos detalhes da ocupação nazifascista e da organização das forças de Resistência italiana. Obras como Lettere di condannati a morte della Resistenza italiana (1952), o diário de Ada Gobetti, Diario partigiano (1956), as memórias de Carla Capponi, Con cuore di donna (2000) e os depoimentos recolhidos em iniciativas como lo sono l'ultimo (2012), entre inúmeros outros, ampliam o conjunto de representantes das memórias do período, manifestando um tipo de literatura bastante ligada à cultura oral, se consideramos o caráter de testemunho e, em alguns casos, a notória urgência do relato, que pede o registro para o conhecimento dos fatos pelas novas gerações. Conforme definiu Márcio Seligmann-Silva (2003a), o efeito estético do fragmento e os conteúdos incompletos são os reflexos verbalizados da experiência traumática. Além disso, são formas literárias que estabelecem ligações mais imediatas com o seu contexto, mesmo que o destaque recaía sobre a dificuldade de narrar certos fatos. Ao lado disso, segundo 
Giorgio Agamben (2008), observa-se uma necessidade extrema de testemunhar, capaz de levar o narrador à vontade de sobreviver para contar.

A relação entre os discursos e os efeitos dos períodos traumáticos que revivem também configura um aspecto singular para o estudo dessas narrativas, possibilitando novas formas de entendimento do resultado estético. Sem dúvida, estamos pensando nas recentes pesquisas na área da literatura de testemunho e, no caso italiano, não podemos deixar de mencionar o romance e o autor que se tornaram paradigma da memória traumática da Segunda Guerra: Se questo è un uomo (1947), de Primo Levi. Sobrevivente de Auschwitz, convicto "de que nenhuma experiência humana é vazia de conteúdo, de que todas merecem ser analisadas; de que se podem extrair valores fundamentais (ainda que nem sempre positivos) desse mundo particular" (LEVI, 1989, p. 88), o autor nos oferece material para as discussões sobre o testemunho de guerras, sobre experiências de segregação, vivências da tortura, da violência e da exclusão social.

Não é novidade afirmar que o registro de Levi compartilha com testemunhos de combatentes da Resistência italiana algumas propriedades de objetos de investigação de grande proveito para os estudos literários e historiográficos, cuja integração vem sendo especialmente rediscutida nos últimos anos. O testemunho pode ter importância tanto pelo valor estético (quando se observam os elementos da narrativa convocados e manipulados pelo discurso) quanto pela relevância do debate (acerca dos direitos desrespeitados, da imposição de supremacias, de ideologias, de interesses materiais) em que se insere. O relato também se torna instrumento de resistência, porque impõe a forma aparentemente despretensiosa como adequada (selando um compromisso estético) para registro de um contexto de conflito, pautado pelo autoritarismo, abuso ou violência (cumprindo um compromisso ético) contra o próprio narrador e contra o outro.

Isso nos faz recordar a perspectiva de Paul Ricoeur (2007), segundo a qual o dever de justiça pode recrutar o trabalho de memória e o trabalho de luto, ou seja, "o dever de memória é o dever de fazer justiça, pela lembrança, a um outro que não o si" (RICOEUR, 2007, p. 101). Lembrar seria dispor-se a fazer justiça ao infortúnio do outro, pois a memória dos que contribuíram para transformar a sociedade deve ser exposta.

Em 2012, demos início ao trabalho de pesquisa com narrativas de ex-partigiani italianos e, graças a um oportuno desvio do percurso, passamos a investigar alguns 
relatos da luta partigiana na região de Trieste, partindo de textos integrantes da coletânea de testemunhos lo sono l'ultimo. Procuramos assinalar o valor histórico e literário dos depoimentos, porém o espaço permaneceu como um critério de seleção dos depoimentos. Elegemos histórias de homens e mulheres, que lutaram na área, com origens italianas e iugoslavas (que hoje seriam eslovenas e croatas). Os testemunhos nos levaram a muitos outros relatos e a uma vasta pesquisa histórica. O objeto se restringe às memórias do final da Segunda Guerra, com destaque para os acontecimentos no nordeste da Itália, sobretudo na fronteira com a atual Eslovênia. De alguma forma, estudar a memória da região de fronteira nos leva a revigorar as histórias de nossa infância, contadas pelos avós croatas e pelo avô filho de italianos. Em poucas palavras, a lógica (ou a coincidência) desta pesquisa se explica nos sobrenomes da autora.

\section{DO DEPOIMENTO INFORMAL À FORMA ARTÍSTICA}

Trieste foi o mais importante porto do Império Austro-húngaro, anexada à Itália após a Primeira Guerra. Na região de Trieste, assim como na de Gorizia, e também na Dalmácia e na Ístria, conviviam os grupos étnicos italiano, esloveno e croata. Com a inclusão ao território italiano, a região desenvolveu o que se chamou de "fascismo de fronteira": a ascensão do fascismo proibiu os idiomas e demais manifestações de culturas estrangeiras, o que provocou situações de revolta e consequências muito graves, na forma de vinganças que marcaram a história da cidade. Mussolini proclamou as chamadas leis raciais em Trieste, cidade com maior população hebraica da Itália, em 1938. Ocupada pela Alemanha nazista desde o armistício de 8 de setembro de 1943, a situação foi desesperadora em termos de repressão. A Risiera di San Sabba foi utilizada como campo de prisioneiros, para os deportados, para detenção e eliminação de partigiani italianos e eslavos, dissidentes políticos e judeus. Há quem afirme que houve cerca de 200 campos na Itália, mas se sabe de 46 campos de concentração e 9 colônias de confinamento. E a Risiera foi o único campo de concentração na Itália e na Europa Meridional, com forno crematório.

No final da guerra, as tropas alemãs resistiram em Trieste até o início de maio de 1945. Enquanto isso, a representação local do Comitato di Liberazione Nazionale (composto de todas as forças políticas antifascistas, exceto comunistas) promoveu 
uma insurreição, e as brigadas partigiane iugoslavas com o apoio do Partido Comunista Italiano atacaram, e ficaram com a fama de terem libertado a cidade, 0 que fez dos partigiani da CLN clandestinos. O exército iugoslavo manteve o controle da cidade até 12 de junho. Os chamados "quarenta dias de Trieste" assistiram a muitas execuções, movidas pela ideologia ou pela vingança pessoal. Durante os massacres, muitos cadáveres foram atirados junto com pessoas vivas nas foibe, cavidades comuns na região.

Em fevereiro de 1945, parte da brigada partigiana Osoppo foi morta por mais de cem partigiani gappistas (dos GAP, gruppi di azione patriottica, nascidos sob iniciativa do Partido Comunista Italiano, o PCI). Dezessete partigiani morreram, entre eles Guido Pasolini, irmão do escritor e cineasta. Tomada como uma das piores histórias da Resistência, é mais um acontecimento trágico dos últimos anos da guerra na região de Trieste, cidade que passou a conviver com praticamente todas as novas rivalidades italianas em seu território, não bastassem as discordâncias históricas entre italianos e eslavos.

Em 1947, Trieste (na verdade, território Livre de Trieste) estava dividida entre o comando dos Aliados e o dos iugoslavos. Em 1954, a cidade foi dividida de fato, segundo as duas administrações. Em 1975, o Tratado de Osimo resolve definitivamente a situação entre a Itália e a então República Socialista Federal da lugoslávia. Trieste é hoje parte da região Friuli-Venezia-Giulia, e faz fronteira com a atual Eslovênia.

lo sono l'ultimo (Eu sou o último) é a coletânea de testemunhos, que tem origem curiosa. Após o depoimento de uma ex-partigiana ser publicado num grande jornal italiano em 2010, a redação recebeu muitas cartas, muitas de outros partigiani, contando suas histórias de cerca de sessenta anos antes. As revelações que motivaram os organizadores do volume estavam ligadas a dois fatos essenciais: primeiro, o de que a guerra partigiana do biênio 1943-1945 possui histórias trágicas e maravilhosas, na iminência de desaparecerem (um dos ex-partigiani utiliza a afirmação "Eu sou o último" quando dá palestras nas escolas, o que faz a plateia se interessar mais); em segundo lugar, a Resistência havia sido um movimento conduzido por jovens, pessoas que naqueles anos de 1940 tinham mais ou menos vinte anos. Ouvir ou ler essas histórias, portanto, é adotar o olhar desses jovens recém-saídos da adolescência, muitos dos quais provavelmente se apaixonaram pela primeira vez em plena guerra (FAURE; LIPAROTO; PAPI, 2012, p. vi). Tudo, 
aliás, deve ter acontecido pela primeira vez naquelas condições tensas e cheias de esperança e coragem.

Entre os depoimentos, chama-nos a atenção o de Milka Cok (nome de guerra “Ljuba”), nascida em Trieste em 1928, estudante e mensageira na atividade partigiana em sua cidade, além de membro da Liga da Juventude Comunista lugoslava. Seu testemunho se destaca como fonte em outras obras, pois já era mencionado desde 1997, no primeiro livro da jornalista Claudia Cernigoi, que trata dos massacres ainda discutidos na região de Trieste. O texto da ex-partigiana, Ljuba, se abre com o relato do gatilho da memória dos tempos da guerra. Ela conta que teve uma hemorragia cerebral poucos anos antes, e as consequências a levaram a pensar que estivesse vivendo os tempos da prisão (a tradução de todas as citações do volume é nossa): "Novamente me salvei: tudo é passado, mas a lembrança permanece." (FAURE; LIPAROTO; PAPI, 2012, p. 171). Assim, dá início ao relato da época em que contava 17 anos de idade, e o episódio escolhido foi o dia da busca efetuada pelos guardas da famigerada banda Collotti, que acordou toda a sua família, cujos nomes estavam registrados com os oficiais.

Instituído por Mussolini em 1942, como corpo de repressão antipartigiana, na Venezia Giulia, o Ispettorato Speciale di Pubblica Sicurezza, com sede em Trieste, foi a única estrutura dedicada exclusivamente para este fim na Itália. Distinguiu-se pela ferocidade dos métodos, com uso sistemático da tortura nos interrogatórios dos antifascistas italianos e eslovenos capturados, mas também contra os simples suspeitos. Há documentação farta apresentada por Claudia Cernigoi (2013), que explora a chamada banda Collotti, parte mais ativa dos membros do Ispettorato que, depois de 8 de setembro de 1943, obedeceu às ordens do comandante das SS dos Adriatisches Küstenland e cometeu vários crimes, sobretudo, mas não somente, contra as minorias eslovena e croata. Gaetano Collotti foi o comandante da referida tropa, que tinha cerca de 180 homens, depois de ter sido, até 1942, vice-comissário do Ispettorato. Collotti viu muitos de seus homens passarem às fileiras partigiane depois do 8 de setembro, porém ele aderiu à Repubblica di Salò, comandada por Mussolini, nos últimos anos da guerra. Na luta contra os opositores do fascismo e na perseguição aos judeus, ficaram famosas as sedes do Ispettorato, nas quais a tortura era frequente: em Trieste havia a Villa Triste (nome pelo qual se tornaram conhecidas as sedes do Ispettorato por todo o país) na via Bellosguardo n. 8 e no quartel de via Cologna, sede central da Banda Collotti, ainda hoje existente. 
Ljuba e sua família foram levados de casa, interrogados, torturados. A moça foi levada para reconhecer partigiani mortos e, ameaçada, resistiu: "Dentro de mim havia um único pensamento: 'Caros companheiros, se não os traí enquanto vivos, tanto menos o farei agora que estão mortos. Morrerei com vocês."' (FAURE; LIPAROTO; PAPI, 2012, p. 172). Após assistir aos saques ou recolhimento dos bens confiscados, no caso, alimentos e animais, Ljuba segue com cerca de 40 conterrâneos para a sede central do Ispettorato. Era 1945, e o comandante Gaetano Collotti, já respondendo à Repubblica di Salò em sua agonia, praticava ele próprio as sessões de tortura, como descreve Ljuba. Depois de uma série de violências, enquanto sua mãe a ouvia na cela vizinha à sala de tortura, o escrivão teve de pegar em sua mão para ajudá-la a assinar a declaração. Chega a ser tocante o modo pelo qual a narradora se refere ao soldado que a ampara. Não por acaso, a lembrança da origem do soldado aparece:

Depois da tortura, me jogaram no cômodo ao lado, no meio de um amontoado de trapos ensanguentados. Sangrava por todas as partes. Depois, Paolino, um jovem soldado calabrês, me acompanhou à cela. Ajudou a me lavar e a me pentear. (FAURE; LIPAROTO; PAPI, 2012, p. 173).

Ljuba pode ter se lembrado da origem do soldado por várias razões, mas apostamos no desejo de humanização do subordinado que teve o mínimo gesto de solidariedade. Como vinha de uma região pobre, e provavelmente estava nas fileiras do Ispettorato pelo soldo, o jovem viu na moça ferida pela tortura o sentido de maior abandono e necessidade de ajuda. Mais que o escrivão que pegara na mão da jovem, para que ela assinasse o depoimento, o soldado calabrês aparece para enfatizar o estado de debilidade da resistente.

Em seguida, Ljuba foi presa no Coroneo, prisão de Trieste em que estavam muitos eslovenos. Não bastasse tanto, ainda corria o boato de que todos poderiam ser levados para Risiera di San Sabba ou para a Alemanha, ou mesmo eliminados. "Os detentos eram levados às escondidas durante a noite. A cada noite se ouvia levarem as pessoas. As mulheres rezavam para são Floriano por medo de terminarem nos fornos da Risiera." (FAURE; LIPAROTO; PAPI, 2012, p. 174).

O depoimento de Nerina de Walderstein comprova as atitudes de conluio entre o comando fascista de Trieste e os nazistas. Segundo a ex-deportada para Auschwitz, sua prisão ocorreu em março de 1944 e, após a via sacra de oito dias de 
torturas na Villa Triste, passou dois meses na prisão dos Jesuítas para seguir para o Coroneo, onde foi interrogada por alemães e detida na cela 68 , da qual quase todos os detentos seguiram para Risiera di San Saba. Nerina seguiu com um grupo de cerca de cinquenta mulheres para Auschwitz, aonde chegou em junho.

"Os carnífices" tinham pressa em se livrar dos prisioneiros. Ljuba segue a pé para o outro lado da cidade, onde seguirá de caminhão para a Alemanha. No entanto, não partem, voltam ao Coroneo e ficam sabendo que a Alemanha estava vencida. Eram os últimos dias de abril, e os triestinos rebelados libertam os prisioneiros. Chegam os partigiani e Ljuba termina seu relato:

\footnotetext{
Veio o primeiro de maio. Já no amanhecer vimos os primeiros partigiani e os acolhemos com grande alegria. Os meus irmãos não estavam entre eles. Mais tarde, o Comitato di liberazione de Longera nos informou que os meus dois irmãos foram mortos em 27 de setembro de 1944. (FAUR; LIPAROTO; PAPI, 2012, p. 174)
}

Diante de certos testemunhos de sobreviventes da violência, o relato de Ljuba não chega a ser impressionante, porém estabelece uma ordenação muito bem pensada para o texto, como se a memória organizada buscasse o efeito crescente no leitor. Em nosso presente, é inevitável não associarmos alguns fatos e imagens aos episódios de violência relatados por sobreviventes de outros regimes autoritários. Sem exageros, pensamos no torturador italiano nazifascista, que fez escola cerca de vinte anos depois na América Latina, assim como confrontamos o depoimento de Ljuba com os de sobreviventes de prisões da ditadura brasileira.

Sutilmente, o depoimento revela aspectos pouco tocados diretamente nos testemunhos recolhidos no volume: o comando nazifascista, por exemplo, já perdia o controle absoluto e não agia incisivamente com os prisioneiros, algumas vezes deixados à própria sorte. Esta observação de entrelinhas marca uma lacuna significativa no testemunho de Ljuba, que não segue uma linha temporal nem encadeia os fatos logicamente, relacionando causa e efeito. Por outro lado, o requinte da tortura é marcante no texto, assim como era regra nas sedes chamadas de Villa Triste. A mãe que ouve a tortura da filha é uma imagem forte, coincidentemente relatada pela mãe de uma prisioneira na Villa Triste de Firenze, em depoimento no documentário La donna nella Resistenza (Liliana Cavani, 1965).

Cabe dizer, finalmente, que depoimentos como o de Ljuba e outros da coletânea lo sono l'ultimo recolocam o debate sobre as atrocidades fascistas na 
região de Trieste. Com as forças do Marechal Tito às portas naqueles últimos anos da Segunda Guerra, o anticomunismo patriótico chegou a ofuscar o antifascismo e a Resistência. Aos acontecimentos repugnantes do final da Guerra, como o massacre das foibe, o episódio de Porzus e o êxodo de italianos dos territórios eslavos, juntam-se às ações de comandantes como Gaetano Collotti, um sujeito que ia à missa todos os dias, antes de seguir para o trabalho.

\section{O TEXTO É O CORPO}

Os depoimentos recolhidos em lo sono l'ultimo, em princípio, poderiam ser classificados no bloco dos resultados da história oral testemunhal. São declarações solicitadas pelos organizadores, algumas obtidas através de entrevista. $O$ volume possui, no entanto, o sugestivo subtítulo Lettere di partigiani italiani. De acordo com o propósito do livro - recolher o maior número possível de depoimentos e documentar da melhor maneira as experiências dos indivíduos nascidos e atuantes nos mais diversos lugares - ele também não deixa de ser um conjunto de cartas endereçadas aos jovens, a quem são confiados o testemunho e a herança da Resistência, pelos que sabem que o tempo se esgota. Em contraponto às cartas dos partigiani condenados à morte, recolhidas nos anos de 1950, cujo impacto ainda respirava a tensão do final do conflito mundial, aqui podemos examinar alguns dos mais recentes testemunhos diretos de alguns protagonistas da guerra de libertação na Itália. Ganhamos, além da elaboração do discurso no presente, também o benefício da organização do relato na maioria dos textos de modo a pressentir 0 efeito da memória sobre a linguagem.

Sabemos que a memória oral é mais espontânea que a memória escrita. Quando o estímulo (como a entrevista) provoca a expressão, no caso da primeira, pode-se observar a liberdade e a menor ocupação com a forma do discurso. A memória escrita implica certas preocupações, pois reorganiza a lógica expressiva. Há sérias considerações, por exemplo, quando se transcrevem depoimentos, para que a identidade do depoente seja preservada, assim como o sentido da sua fala, especialmente em certas marcas, como sotaque, emprego da sintaxe, repetições, ênfases. Quando os testemunhos são escritos, a forma pode e deve ser observada por meio da análise do discurso ou da (nova) expressão literária latente. 
Se pensarmos nessas narrativas de lo sono l'ultimo como depoimentos, temos um problema ao tentarmos vê-las como literatura: analisá-las segundo os parâmetros convencionais da Teoria Literária. O valor estético dos testemunhos não se pontua exclusivamente pelas categorias aristotélicas relativas à mimese. $\mathrm{Na}$ perspectiva de Márcio Seligmann-Silva, os testemunhos apresentam uma voz traumatizada, um tom de lamento e de denúncia que se fazem presentes, dispostos a narrar uma experiência vivida, malgrado todas as dificuldades de expressão. Poderíamos aqui recorrer a uma famosa fala de um professor em um filme americano, e dizer que ao explorar as narrativas de testemunho, como formas literárias, não estamos estudando literatura apenas porque é bela. Preferimos explorar algumas considerações de Giorgio Agamben, cuja análise do relato de Primo Levi é exemplar.

Em seu La tregua, relato que se inicia no ponto em que termina Se questo è un uomo, Primo Levi recorda Hurbinek, um menino de três anos, morto após ser libertado de Auschwitz, incapaz de verbalizar sua história, liberto, porém não redimido (LEVI, 1989, p. 167); Levi assume a palavra que Hurbinek não possui e declara (tradução nossa): "ele testemunha através destas minhas palavras" (LEVI, 1989, p. 167). Convicto da sobrevivência para condicioná-la à necessidade de contar a história dos que foram privados da linguagem, Levi mantém o sofrimento e assume a voz do outro, conservando a memória dele. Mais que isso, preserva o sentido de "testemunha" em sua completude, isto é, mantém o correspondente de testemunha em grego, denominado martis (em português, mártir). Embora "o que aconteceu nos campos pouco tenha que ver com o martírio" (AGAMBEN, 2008, p. 35), o sentido ainda permanece quando observamos que o termo martis deriva da mesma raiz de "recordar".

Martirizar-se, portanto, pode significar a exposição do corpo e da alma sofridos para recordar uma convicção. Testemunhar sobre o acontecimento traumático da guerra, da tortura, do sofrimento, quase sempre, é sofrer um martírio, que não se realiza sem a memória, muitas vezes descontínua, com lacunas, dissociações discursivas, relato interrompido e retomado - Agamben diz que "o testemunho vale essencialmente por aquilo que nele falta" (AGAMBEN, 2008, p. 43). O texto escrito se esforça na reconstrução dessas interrupções, no preenchimento das lacunas, porém o discurso permanece desarticulado como uma linguagem da qual foi retirada 
alguma coisa, por vezes se mantendo "uma linguagem mutilada e obscura" (AGAMBEN, 2008, p. 46).

\section{NOTA}

${ }^{1}$ Professora assistente do Departamento de Letras Modernas UNESP-FCL-Assis.

\section{REFERÊNCIAS}

AGAMBEN, Giorgio. A testemunha. In: O que resta de Auschwitz: o arquivo e a testemunha (Homo Sacer III). Trad. Selvino J. Assmann. São Paulo: Boitempo, 2008. p. 25-48.

BURKE, Peter. História como memória social. In: Variedades de história cultural. Trad. Alda Porto. 2. ed. Rio de Janeiro: Civilização Brasileira, 2006.

CERNIGOI, Claudia. La "Banda Collotti": storia di un corpo di repressione al confine orientale d'Italia. Udine: Kappa vu, 2013.

CERNIGOI, Claudia. Operazione Foibe a Trieste. Udine: Kappa Vu, 1997.

CHABOD, Federico. L'Italia contemporanea (1918-1948). Torino: Einaudi, 1961.

FAURE, S.; LIPAROTO, A.; PAPI, G. Io sono l'ultimo: lettere di partigiani italiani. Torino: Einaudi, 2012.

HATLEY, James. Suffering witness. New York: State University of New York, 2000.

LEVI, Primo. Se questo è un uomo: la tregua. Torino: Einaudi, 1989.

RICOEUR, Paul. A memória, a história, o esquecimento. Trad. Alain François et al. Campinas: Ed. da Unicamp, 2007.

SELIGMANN-SILVA, Márcio. Apresentação da questão. In: memória, literatura. Campinas: Ed. Unicamp, 2003a. (Org.). História, . O testemunho: entre a ficção e o real. In: (Org.). História, memória, literatura. Campinas: Ed. Unicamp, 2003b.

WALDERSTEIN, Nerina. Depoimento em Testimonianze dai lager: immagini, luoghi e memorie dei sopravvissuti dai Campi di sterminio nazisti. Disponível em: $<$ http://www.testimonianzedailager.rai.it/testimoni/test_25.asp >. Acesso em: 13 out. 2013. 